\title{
TRABAJO INFANTIL; LOS RIESGOS LABORALES EN SITUACIONES LEGALMENTE PROHIBIDAS Y SUS CONSECUENCIAS PARA LA SALUD Y SEGURIDAD
}

\section{CHILD LABOR; THE RISKS IN LABOR CONDITIONS LEGALLY PROHIBITED AND ITS IMPLICATIONS FOR HEALTH AND SAFETY}

\author{
PILAR NOVA MELLE(1)
}

(1) Departamento de Tendencias Sociales. Facultad de Sociología. Universidad Nacional de Educación a Distancia (UNED). Madrid. España.

\section{RESUMEN}

El trabajo infantil está prohibido por todas las legislaciones, a pesar de ello son millones de niños los que trabajan en el mundo. Si las condiciones de trabajo de los adultos son en muchos casos nocivas desde el punto de vista de la seguridad y la salud, los niños las sufren doblemente; por realizar trabajos rechazados por los adultos y por su fragilidad física.

El hecho de desarrollar un trabajo impide que muchos de ellos estén escolarizados, así sus condiciones de trabajo no tienen posibilidad de mejorar y se perpetúa el círculo de la pobreza.

Palabras clave: Trabajo infantil, legislación laboral, escolarización, pobreza, condiciones de trabajo, salud.

(Med Segur Trab 2008; 54 (213):9-21)

\begin{abstract}
Child labour is prohibited by all laws, despite this are millions of children who work in the world. If the working conditions of adults are often detrimental from the standpoint of safety and health, the children suffer doubly, for work rejected by adults and by his physical frailty.

The fact develop a work prevents many of them attend school and their working conditions have no possibility of improving and perpetuating a cycle of poverty.
\end{abstract}

Key words: Child labor, employment law, education, poverty, working conditions, health.

(Med Segur Trab 2008; 54 (213):9-21)

\footnotetext{
Correspondencia:

Dña. Pilar Nova Melle

Dpto de Tendencias Sociales

Facultad de Sociología

Universidad Nacional de Educación a Distancia (UNED)

c/ Obispo Trejo s/n 28040 Madrid (España)

Tef: 913987047

fax: 913987653

pnova@poli.uned.es
} 


\section{INTRODUCCIÓN}

Las situaciones de extrema pobreza en las que viven millones de familias en el mundo, careciendo de lo más elemental para subsistir es la principal causa del origen del trabajo infantil.

La mano de obra infantil es un fenómeno más o menos regulado desde la Revoluciòn Industrial, con anterioridad existía en las comunidades agrícolas como un elemento cultural. Es a partir de la Revolución Industrial cuando la incorporación de los niños al trabajo no guarda relación con las costumbres ancestrales de las diferentes sociedades sino que es algo anómalo, fruto de la necesidad económica de las familias para sobrevivir.

Inglaterra pioniera en la industrialización, también fue pionera en la promulgación de leyes laborales que protegían a la infancia, así en 1819 prohibió el trabajo de niños menores de 9 años en el textil. En 1833 el Parlamento inglés prohibió todo tipo de trabajo a los menores de esta edad, al tiempo que limitaba los horarios por tramos de edad: de 9 a 13 años podían trabajar un máximo de 8 horas al día y de 13 a 18 años un máximo de 12 horas al día. Tres años después, en 1836, Alemania promulga una ley similar a la inglesa, si bien además introduce la limitación del trabajo nocturno a los menores de 16 años. Francia en 1841 establece por ley que los menores de 8 años no podrán trabajar en talleres con motores mecánicos, ni allí donde se agrupen más de 200 trabajadores en un sólo taller. A partir de estas primeras leyes de protección a la infancia se desarrollaron otras de similares características en las que el sujeto a proteger es la mujer.

En España hubo un vacío legislativo hasta principios de siglo XX en lo relativo a la reglamentación del trabajo. A lo largo del siglo XIX triunfan en España, las opiniones contrarias al intervencionismo del Estado en materia laboral, ancladas en la concepción de las relaciones entre empresarios y trabajadores como libremente pactadas por ambas partes.

No obstante, la primera ley que reguló en España el trabajo de menores en fábricas, talleres, fundiciones y minas se promulgó en 1873 , fue también llamada ley Benot. ${ }^{1}$
En la misma se estipulaba que no podían ser admitidos los menores de 10 años de ambos sexos. Los niños menores de 13 años (14 en el caso de las niñas) deberían tener una jornada laboral que no podía superar las cinco horas diarias, siendo de ocho horas máxima para los jóvenes de 13 a 15 años y las jóvenes de 14 a 17. Los efectos en la prática, que tuvo la promulgación de esta ley fueron mínimos, según se puede comprobar en los distintos documentos de la época. Será en 1900 cuando se apruebe una ley sobre el trabajo de mujeres y menores, así como de accidentes de trabajo, la que tendrá más repercusión. En este caso se conoció como ley Dato $^{2}$. El año 1900 fue no sólo muy productivo en materia de legislacion laboral, sino que las normas aprobadas tuvieron una gran repercusión en las pauperrimas condiciones de la clase obrera, como la mencionada Ley Dato que paliaba las consecuencias económicas que tienen para los trabajadores y sus familias los accidentes de trabajo, al tiempo que fue el germen de lo que posteriormente se generalizó como seguridad social.

Aunque con poco calado de la mayoria de las leyes, los diferentes gobiernos proseguian con su objetivo legislativo. Una de las normas dirigidas a la protección de la infancia de gran importancia fue el Real Decreto del Ministerio de la Gobernación de 25 de enero de 1908 en el que se prohíbe el trabajo de los menores de 16 años en minas y canteras y en las labores de corte y extracción, de la misma manera prohibe el transporte de mineral sobre la cabeza y a hombros en las galerías.

En el medio rural el trabajo infantil era algo generalizado y se iniciaba a edades muy tempranas (4-7 años según los casos) ${ }^{3}$. En consecuencia la ausencia de los niños en las escuelas rurales era algo también habitual. Como se verá la falta de formación por una desescolarización prematura es otra de las causas del trabajo infantil.

Según este mismo autor en 1923 la inmensa mayoría de los niños abandonaba la escuela a los 1011 años. Porque si bien en esa fecha la edad escolar abarcaba hasta los 14 años la asistencia a la escuela realmente no era obligatoria.

A pesar del esfuerzo legislativo los niños continuaban trabajando, pues la mano de obra infantil era

(1) Eduardo Benot, Ministro de Fomento, Ley 24/07/1873 de limitación de la edad laboral.

(2) Eduardo Dato, Ministro de la Gobernación, Ley 31/01/1900 de accidentes de trabajo.

(3) Borrás Llop, J.M. (2002) El trabajo infantil en el mundo rural entre 1849 y 1936 en Martínez Carrión (editor), El nivel de vida en la España rural, siglos XVIII-XX. Universidad de Alicante. 
una a portación muy importante en la actividad económica general española del siglo XIX y principios del XX, prácticamente hasta la II Republica. Época en la que la cuestión social adquirió una relevancia de primer orden.

La adopción de medidas, fue cada vez más generalizada en los países europeos, pero en la primera década del siglo XX, por citar el país que inició la legislación laboral de protección a la infancia, Inglaterra, solamente en el sector textil, había 120.000 niños menores de 13 años trabajando. Las condiciones de trabajo eran difíciles y peligrosas, dado que las leyes no consiguieron hacerlas cambiar. El medio rural era ajeno a la normativa, ciertamente estaba pensada para la industria.

La situación actual en el mundo sigue recordando los siglos pasados. El trabajo infantil es una constante en aquellos países que aspiran a industrializarse, sobrepasando la sutil línea que convierte el trabajo en explotación.

La UNICEF marca unos criterios básicos para determinar si el trabajo infantil es explotación, estos son:

- Si es con dedicación exclusiva.

- Si es a una edad demasiado temprana.

- Si provoca estrés físico, psíquico o social.

- Si el niño trabaja y vive en la calle.

- Si el salario es inadecuado.

- Si el niño tiene que asumir demasiada responsabilidad.

- Si impide el acceso a la escolarización.

- Si mina la dignidad del niño (esclavismo/explotación sexual).

- Si impide conseguir un pleno desarrollo.

Por su parte la ONU en la aprobación Declaración de los Derechos del Niño ${ }^{4}$ establece, entre otros, los siguientes principios:

El niño tiene derecho a crecer y desarrollarse en buena salud (P.4).

El niño tiene derecho a recibir una educación que permita desarrollar sus aptitudes (P.7). (P.7)

El niño debe disfrutar de juegos y recreaciones

(4) 1959, ONU, Asamblea General, 20 de noviembre.
El niño será protegido contra toda forma de abandono, crueldad y explotación (P.9).

No obstante si bien la explotación infantil es condenada universalmente, en cuanto al trabajo infantil, en algunas de sus formas existe discrepancia sobre su eliminación o no. Las razones argumentadas a favor son las características culturales de algunos pueblos en los que el trabajo infantil es una estratégia pedagógica y de socialización.

A lo largo de las siguientes páginas se describe el panorama mundial del trabajo infantil en la actualidad, con las características que lo determinan en cada caso, comprobando como en la práctica se confunden los conceptos.

\section{EL TRABAJO INFANTIL EN EL MUNDO}

Los insuficientes ingresos familiares convierten a los niños en mano de obra necesaria. La situación de muchas familias sin esta aportación de los niños sería insostenible.

Así el trabajo infantil se convierte en una parte muy importante de un entramado económico y su desaparición inmediata pondría en serios aprietos no sólo a las familias sino también a las economías de muchas zonas.

Su trabajo es necessario para su propia subsitencia y la de sus familias y aunque el ideal es que cesen las actividades, los expertos tanto de ONG'S, principalmente Save The Childen como la propia OIT, darían por bueno que se cumpliesen al menos tres objetivos básicos:

1. Que sea compatible con la escuela.

2. Que tengan buenas condiciones de seguridad e higiene.

3. Que acabe todo tipo de explotación.

Además en algunos ámbitos el trabajo infantil es culturalmente aceptado y valorado, por ejemplo en la agricultura donde los padres trasmiten sus saberes y los niños al tiempo que trabajan construyen su identidad campesina. Ante esto hay dos posiciones; una, los que ven en las tradiciones la gran barrera para eliminar el trabajo infantil. Dos, los que consideran que adquieren conocimientos, aprenden a asumir responsabilidades, se integran socialmente en su comunidad, etc. La propia OIT no se opone si este trabajo es adecuado a su edad y madurez. 
El problema real es que el trabajo infantil no es algo coyuntural del sistema productivo sino que es un elemento importante en la expansión de la economía de mercado.La utilización de mano de obra infantil interesa a muchos empleadores porque los salarios son menores, son más manejables que los adultos y más vulnerables a las amenazas. La mayoría de los niños trabajadores forman parte de un mercado laboral informal, familiar y limitado al entorno local, teniendo como consecuencia su invisibilidad a los marcos jurídicos que protegen al resto de los trabajadores. Razón por la que el trabajo infantil ha sido siempre un fenómeno socioeconómico de díficil cuantificación. La OIT evalúo por primera vez en 1995 el número de trabajadores infantiles en el mundo.

Según los datos facilitados por la OIT en 2007 había 218 millones de niños/as trabajando en el mundo. De los cuales 165 millones tiene una edad comprendida entre 5 y 14 años. La mayor parte lo hace en la agricultura; 130 millones. Más de 10 millones en el trabajo doméstico. El trabajo doméstico es la primera ocupación de las niñas menores de 16 años en todo el mundo, 1 millón en la mineria, 1,8 millones son explotados sexualmente en el sector turístico. En torno a 300.000 niños soldados ${ }^{5}$ participan en guerras.

Entre el 10 y el $15 \%$ de los empleados en el sector del turismo y el ocio en todo el mundo son menores de 18 años.

Además de 1,2 millones de niños son victimas de la trata infantil, incluido el tráfico de órganos y la adopción ilegal.

La región de Asia y el Pacífico tiene el nivel más alto de niños trabajadores, según la OIT son aproximadamente 122 millones los niños de entre 5 y 14 años los que trabajan en esa zona del mundo. La situación recuerda el panorama del siglo XIX. Por ejemplo, India que desde el año 2006 prohibe el trabajo a menores de 14 años, admite que es díficil aplicar la ley y calcula más de 13 millones de niños por debajo de esa edad trabajando.

Se debe tener en cuenta que según los datos de Naciones Unidas, el país tiene apróximadamente a
300 millones de personas viviendo por debajo del umbral de la pobreza.

En segundo lugar el continente africano, concretamente la zona subsahariana con 50 millones de niños trabajadores y en tercer lugar esta América Latina y el Caribe, con niños trabajadores en la práctica totalidad de los países excepto Cuba, destacando en primer lugar Perú. Si bien en los últimos 4 años ha descendido en un $11 \%$ el número de niños trabajadores fundamentalmente en Brasil.

Aunque de forma natural se identifica el trabajo infantil con países en desarrollo, en los países occidentales, llamados desarrollados, con legislaciones adecuadas en materia política, laboral e infantil además de cierta sensibilidad hacia la infancia, no escapan a este fenómeno. Así por ejemplo en Italia en el año 2002 se calculaba cerca de 400.000 niños trabajando $^{6}$ en la agricultura y en la economía sumergida. Estimando en 144.000 el número de menores excluyendo a los niños inmigrantes ${ }^{7}$. Según un estudio realizado por la Fundación del Banco de Napoles, entre los niños que trabajan de 7 a 10 años, más del $80 \%$ pertenecen a familias que están bajo o en el límite del umbral de la pobreza. Entre estos niños, en la franja de 13-14 años se registra un abandono de la escuela secundaria en el último año (14 años) cercano al $70 \%$.

En España se calcula en torno a 170.000 niños que cuando vuelven de la escuela a sus casas trabajan como "ayuda familiar" en diferentes tareas, destacando el trabajo doméstico, agrícola, ganadero y la venta.

La media europea es de 1,5\%. Aparentemente es una situación limitada, coyuntural y bajo control, pero estos niños corren el riesgo de abandonar la escuela de forma precoz, más si cabe si son hijos de inmigrantes en dificultades socioeconómicas. El mero hecho de trabajar es ya una forma de exclusión social, cultural y económica que da lugar a la autoreproducción de la pobreza y la exclusión cuando sean adultos. El gran problema de los países ricos es no reconocer la existencia del trabajo infantil, porque en estos países las vías de solución existen.

Ante la magnitud del problema, la OIT decidió

(5) 2007. Dato procedente de Amnistía Internacional

(6) 2002. Instituto de Investigaciones Económicas y Sociales. (IRES)

(7) 2002. ISTAT

(8) 2001. UNICEF, Comité Español. 
establecer un día mundial contra el trabajo infantil; se celebra desde el año 2002.

Cada año la OIT elige un tema para ser tratado a nivel mundial, considerando prioritarios aquellos trabajos más penosos para la infancia y por tanto de más urgente erradicación.

El año 2003 fue dedicado a la explotación sexual, el 2004 al trabajo doméstico, el 2005 a minas y canteras, el 2006 a la eliminación del trabajo infantil: un objetivo a nuestro alcance, el 2007 a la agricultura y este año 2008 a la educación como alternativa al trabajo infantil.

\section{CONDICIONES DE TRABAJO POR SECTO- RES Y CONSECUENCIAS PARA LA SALUD Y SEGURIDAD}

\section{a) Agricultura}

Son aproximadamente 130 millones los niños que trabajan en los campos y plantaciones de diferentes países del mundo ${ }^{9}$, en los campos de arroz, café, cacao, azúcar, té, palma de aceite, algodón, etc. Tienen entre 5 y 14 años.

A pesar de ser un trabajo relativamente "oculto" a los ojos de la opinión pública, se estima que cerca del $70 \%$ de los niños que trabajan lo hacen en este sector $^{10}$

Son niños que habitan en el medio rural, pero su trabajo no es sólo de ayuda en la pequeña propiedad familiar, como subsistencia o como economía comercial, sino que también están empleados por cuenta ajena.

El trabajo que realizan conlleva una serie de riesgos debido a la manipulación de herbicidas y pesticidas, al uso de maquinaria pesada e instrumentos punzantes y cortantes, herramientas diseñadas para adultos, sufriendo cortes en piernas y manos. Presentan sintomas propios de la inhalación de sustancias tóxicas; dolor de cabeza, de estómago, mareos, irritación de nariz y ojos, nauseas, picazón,etc.

Transportan cargas pesadas desde el campo hasta las plantas de empaquetado, con los consiguientes riesgos para su desarrollo óseo. Las niñas están doblemente desfavorecidas, ya que, con frecuencia asumen tareas domésticas después de su jornada en el campo.

$\mathrm{Su}$ salario es como media dos tercios menos que el salario de un adulto.

Ciertamente no todos los niños están empleados a tiempo completo, algunos de ellos lo hacen compatible con la asistencia a la escuela, pero al ser la agricultura un trabajo estacional, hace que en periodos de recolección muchos se ausenten. Además el sector rural en muchas zonas del mundo carece de escuelas, si los niños deben recorrer largas distancias para asistir a la escuela es un elemento disuasor, en consecuencia las probabilidades de incorporarse a los trabajos agrícolas son altas.

Finalmente un porcentajre de estos niños huyendo de la pobreza y de las condiciones de vida del medio rural emigraran a las ciudades donde se incorporan a trabajos precarios en el mejor de los casos, algunos se suman a la cifra de "los niños de la calle".

\section{b) Mineria}

La dispersión geográfica, la variabilidad de horarios, el carácter familiar, el carácter informal en definitiva de muchas extracciones artesanales hacen muy difícil detectar cuántos niños, con qué horarios y con qué edad trabajan en el sector minero. Además hay muchos niños que combinan el trabajo y la escuela, éstos no serán computados como trabajadores, su tarea se considera una "ayuda".

En las minas los pasillos son bajos y estrechos, así los niños tienen un tamaño ideal para el trabajo. Es frecuente que los niños trabajen en las minas de oro de Côte d'Ivoire en Africa, en las canteras de piedras de Nepal, en las minas Madre de Dios en Perú, en el carbón en Nalaikh en Mongolia...

Expuestos a la muerte por derrubes, los que sobreviven cuando se produce un hundimiento pueden quedar discapacitados de por vida. Realizan largas jornadas de trabajo sometidos a temperaturas extremas, a ruído, vibraciones, alto grado de humedad, a vapores y polvos nocivos que les causan problemas respiratorios, también es frecuente que se produzcan explosiones accidentales por concentraciones de gas. En las minas de oro pueden sufrir

(9) 2007. OIT: Informe junio

(10) 2006. UNICEF. Informe sobre la explotación infantil: protección contra el abuso y la violencia. 
envenenamiento por el mercurio, debido a su uso en el proceso de extracción de oro de la mena.

Las enfermedades que los niños contraen en la mina son: silicosis, cáncer de la cavidad nasal, bronquitis, pérdida auditiva, ruptura traumática del tímpano, traumatismo muscolo-esquelético, cortes, asfixia, etc.

El objetivo no es trabajo más seguro para los niños cambiando de actividad, por ejemplo pasando en la mina de la excavación al transporte, porque todo trabajo tiene riesgos, con estas medidas se evitan unos riesgos y se exponen a otros: no hay trabajo seguro. Los niños que han cambiado de tarea también padecen problemas; musculares y de espalda por el peso que transportan con el material extraido.

En las minas de Tanzania, por ejemplo, para obtener piedras preciosas con apenas 8 o 9 años se adentran 30 metros en el interior de la tierra, cavando pasadizos sin ventilaciòn y sin apenas luz ${ }^{11}$.

En otros países como Brasil el 4\% de la población que extrae y produce mineral son niños de entre 5 y 17 años, un total de $145.900^{12}$.

No obstante Brasil es uno de los países que esta adoptando medidas para poner fin a esta situación, como; establecer acuerdos con el sector minero para que no de empleo a los niños, incentivar a los camioneros que denuncien la explotación infantil en las minas, legalizar muchas minas artesanales para controlar el trabajo en las mismas, ya que han detectado que se produce en minas no legalizadas.

Las niñas que no trabajan en la mina o en alguna parte del proceso, ayudan a sus madres a la elaboración y venta de alimentos para los mineros. Para llegar a sus clientes deben atravesar zonas peligrosas expuestas a derrumbamientos, contaminación por mercurio y otros peligros, transportando cargas pesadas varias veces al día.

\section{c) Servicio doméstico}

Los niños y, fundamentalmente las niñas, el $90 \%$, ocupados en el sector doméstico son los más invisibles de todos los niños que trabajan. Aunque se desconoce con exactitud la cifra, todos los organismos y expertos coinciden en que es el segundo sector después de la agricultura a la hora de contratar mano de obra infantil.

Las cifras aproximadas de la OIT arrojan una cantidad en torno a los 10 millones, destacando Indonesia con 700.000, Marruecos con 500.000, Haiti con 250.000, Pakistán con 264.000, Kenia con 200.000 , etc. Hay que tener en cuenta la edad de estos niños, el $10 \%$ de los niños domésticos en Haiti tienen menos de 10 años y el 70\% de los de Marruecos tiene menos de 12 años. ${ }^{13}$

Los padres envian a sus hijos a trabajar en una casa privada, generalmente del campo a la ciudad, en ocasiones como pago a una deuda contraida, pero además piensan que esta es la "menos mala" de las formas de trabajo para sus hijos, consideran a los empleadores como una extensiòn de la familia. El trabajo doméstico para una niña se considera como algo natural, una prolongación de la función que realiza en su propia familia. Universalmente las tareas domésticas tienen una connotación de género y por tanto, las niñas a priori están destinadas a ello; "ignorar las asimetrias de género en relación con el trabajo infantil doméstico significa ignorar a las niñas y reforzar la invisibilidad y devaluación de su trabajo" 14 esta diferencia en el tratamiento contribuye no sólo a perpetuarlo sino además a no considerarlo trabajo.

No siempre las familias que los reciben son de economía saneada por lo que trabajan a cambio de la manutención, no aportan ingresos a la economía de su familia; simplemente han dejado de ser una carga.

Estos niños son muy vulnerables; con frecuencia son explotados laboralmente, y sufren abusos sexuales pero al ocurrir en el ámbito de lo privado, es difícil de detectar, ellos no lo pueden denunciar están lejos de su familia y ésta puede ignorar lo que sucede a la niña; las violaciones de estas niñas quedan en el anonimato.

También trabajan para su propia familia. Muchas niñas no van al colegio porque se deben ocupar de sus hermanos menores y de las tareas domésticas en sus casas para que sus padres puedan trabajar fuera del hogar, evidentemente es una forma de trabajo infantil aunque no este contabilizada como tal.

(11) www.ilo.org/childlabour

(12) 2005. Instituto Brasileño de Geografía y Estadística.

(13) 2004.OIT Informe sobre el trabajo doméstico infantil.

(14) 2005. Pérez, M. CIMAC, México. 


\section{d) Trabajo en la calle}

Aunque por definición la economía informal es invisible, los niños y niñas que trabajan en la calle son la parte más visible del trabajo infantil.

Algunos de los trabajos realizados por los niños en la calle son: la venta ambulante, la limpieza de coches, espectáculos callejeros, repartidores, guías turísticos, recogida de basura, mendicidad, prostitución...

Están expuestos a todo tipo de agresiones, robos, mafias etc. Además de los peligros propiamente urbanos como el tráfico. Sobre el trabajo de los niños en la calle no existen cifras fiables, debido por una parte a su carácter itinerante y por otro lado a que cuando son localizados por la policía quedan registrados en el capítulo de mendicidad.

El Código Penal español en su artículo 232 establece penas de prisión para aquellos que utilicen o presten menores de edad o incapaces para la práctica de la mendicidad, penas que se incrementan si estas prácticas van acompañadas de violencia, intimidación o administración de sustancias.

\section{e) Explotación sexual}

La expoltación sexual de la infancia ha existido durante siglos como parte de tradiciones históricas y culturales. Hoy diferentes circunstancias como las crisis económicas, las guerras tribales en África y otros conflictos armados en distintas partes del mundo, la transición a la economía capitalista en la Europa del este, etc. han incrementado el fenómeno deslingándolo de lo cultural y transformándolo en un asunto meramente mercantil o de abuso de poder, los casos más significativos son el turismo sexual en India, Filipinas, Tailandia, etc y los abusos cometidos por los destacamentos militares en Kosovo, Mozambique, Camboya, etc.

Sin olvidar que los niños son especialmente vulnerables a los abusos sexuales en el ámbito doméstico y laboral.

En los últimos años la explotación sexual de los niños se ha incrementado notablemente a través del turismo sexual. Así desde 1993 varios países han promulgado leyes extraterritoriales para perseguir fuera de sus fronteras y llevar a los tribunales de su país de origen a los turistas sexuales.

Además de las secuelas psicológicas que marcan a los niños de por vida muchos de ellos contraen enfermedades venéreas o SIDA.

\section{f) Matrimonios infantiles ${ }^{15}$}

Casar a una hija siendo niña es otra de las formas utilizadas por las familias para enfrentarse a la precariedad económica. Pero no sólo se valora el aspecto económico, los padres consideran que la hija casada "está protegida" ante tantos abusos sexuales a las niñas.

Según la Unicef, los 82 millones de niñas que en 2003 tenían entre 10 y 17 años en la India, estarian casadas antes de cumplir los $18^{16}$. En la India se necesita dote para casar a una mujer, cuanto más joven es la mujer menos cuantiosa es la dote, razón por la que muchas niñas son sacadas de la escuela para casarlas. Los matrimonios muy jóvenes se explican también por una tradición muy arraigada sobre todo en el medio rural. En el mes de mayo con la celebración de Akshaya Tritya (auspicioso para el matrimonio) los padres casan a sus hijos, éstos pueden tener incluso 6 o 7 años, después de la ceremonia cada uno vuelve otra vez a su casa con sus padres, cuando la novia tiene la primera menstruación se hace la entrega al marido. ${ }^{17}$

Es una costumbre muy arraigada entre trabajadores agrícolas de casta baja que se aferran a sus raíces como forma de aceptación social. En diciembre de 2006 el Parlamento de la India aprobó una ley que invalida los matrimonios entre niños. La edad legal de contraer matrimonio son los 18 años.

Los matrimonios infantiles son también muy frecuentes en Africa Subsahariana.

Los cuerpos infantiles no tienen el desarrollo necesario para la gestación, así se producen muchos partos prematuros, los niños nacen con menos peso, mueren más neonatos; el riesgo de morir antes de cumplir un año se duplica respecto a un bebé nacido de una madre de más de 20 años.

(15) Los matrimonios de niños no son evidentemente una forma de trabajo infantil pero guardan relación con el hilo conductor de la argumentación de este artículo, por ello es incluido.

(16) 2003. UNICEF, Informe sobre el Estado de la Población Mundial (FNUAP-2003).

(17) 2005. UNICEF, Inforne sobre Los matrimonios prematuros, Abril. 
Se calcula que llegan a morir más de 500.000 mujeres al año por causas relacionadas con el embarazo, más de la mitad de las muertes se concentran en India, Nigeria, República Democrática del Congo, Afganistán, Etiopía y Sierra Leona. Las niñas tienen cuatro veces más posibilidades de morir $^{18}$.

Los matrimonios infantiles los sufren más las niñas, lo que contribuye desde otra faceta a perpetuar la discrimación para ellas y sus hijos. El informe de Unicef sobre el Estado Mundial de la Infancia de 2007 recalca la importancia que tiene la igualdad de géneros para la mejora de la infancia. Si las mujeres no reciben educación y no tienen buena salud, lo sufren sus hijos. Si se acabase con la discriminación se obtendría un gran beneficio para la infancia.

Recordemos que la Declaración Universal de los Derechos Humanos (1948) establece el derecho a elegir y aceptar libremente el matrimonio.

\section{g) Niños soldados}

En la Europa Medieval, los niños eran utilizados como asistentes en la batalla (escuderos), aunque su intervención en los combates era muy limitada. El reclutamiento de niños soldados ha visto un repunte en los conflictos del siglo XX y en la primera década del actual.

Según Amnistía Internacional actualmente en más de 30 países donde hay algún tipo de conflicto están participando niños o adolescentes, países como: Burundi, Costa de Marfil, Liberia, Sierra Leona, Sudán, Uganda, Somalia, República Democrática del Congo, están entre los que han obligado en algún momento a los niños a participar en las guerras y enfrentamientos tribales.

En la República Democrática del Congo desde 1996 los niños combatientes en todos los grupos armados del país representan el 35\% de las tropas ${ }^{19}$

El reclutamiento no siempre es forzoso en países como Estados Unidos, Gran Bretaña, Colombia, Irak o Afganistán es legal reclutar a jóvenes de menos de 18 años.

Otras causas que conducen a los niños a participar voluntariamente en guerras son la necesidad de comida, la necesidad de un grupo de acogida ya que muchos son huerfanos precisamente por las guerras o la necesidad de reconocimiento entre pares.

Los niños en los conflictos armados realizan funciones de escudos humanos, de reclamo, detectores de posiciones enemigas, detectores de minas, porteadores de munición, cocineros, y si son niñas además de luchar sirven de esclavas sexuales a los militares.

En 2004 diferentes ONG'S presentaron un escrito al Consejo de Seguridad de Naciones Unidas solicitando que lleven al Tribunal Penal Internacional a aquellos que reclutan niños soldados.

\section{h) Otros trabajos}

El sector manufacturero no es el que emplea mayor número de niños pero es el que más claramente retrata el perfil del trabajo infantil; niños cosiendo balones, tejiendo alfombras... porque denota una mayor organización.

Los países desarrollados propietarios de las firmas comprueban que es menos competitivo producir en su país y siguiendo los principios de la competencia internacional deslocalizan sus empresas. Así con el cambio del lugar de la producción ahorran, lo que no pagan en salarios y seguros sociales lo revierten a la partida presupuestaria de la publicidad, el gran mago que incrementa las ventas.

Normalmente, cuando no construyen una planta propia, el proceso es de contratación con una empresa local, después ésta subcontrata a otra y así sucesivamente hasta llegar en muchos casos a subcontratas tan pequeñas que se produce en casas particulares, aquí es fácil encontrar a niños trabajando.

Pakistán, por ejemplo, fabrica el $60 \%$ del mercado de balones de Estados Unidos, se calcula que son más de 7000 niños cosiendo balones. Las ONG'S pidieron a la FIFA que no ponga su sello a los balones hechos por niños. En España los sindicatos CCOO y UGT formularon una petición al Comité Olimpico Internacional para que impida que sus empresas patrocinadoras utilicen material producto de estas prácticas. Las campañas realizadas contra los balones de futbol cosidos por niños en Pakistán y la reacción de la FIFA y la UEFA hizo que las con-

(18) 2007. FNUAP, Estado de la población en el mundo.

(19) 2007. Datos de Amnistía Internacional y Save the Childen 
diciones de trabajo de estos niños mejorase con programas concretos. En 1996 las ONG'S lanzaron un lema: "los niños no deben jugar con balones que han hecho otros niños pobres en otra parte del mundo".

No siempre el resultado es tan positivo, Michel Hansenne, ex-director de la OIT, pide prudencia en las denuncias citando como ejemplo la campaña contra trabajo infantil en el textil en Bangladesh que tuvo como consecuencia que muchos niños se quedaran sin trabajo y acabaron en la prostitución.

Grandes firmas de ropa de vestir y de ropa de deporte de Europa y Estados Unidos producen sus prendas en India, Marruecos, Honduras, Indonesia, Bulgaria, Tailandia, Turquia, China, etc. Las realizan mujeres y niños con horarios de hasta 13 horas, presionados por los plazos de entrega, siendo las horas extraordinarias una práctica habitual y sin remunerar en muchos casos, con salarios miseros, en locales que no reunen las más mínimas condiciones de seguridad e higiene en el trabajo.

Entre las empresas españolas del sector textil, también es una práctica habitual el trasladar su producción a Marruecos, cuando las ONG'S denuncian el hecho por no respetar los convenios de la OIT, los derechos humanos básicos e incluso la legislación local, estas empresas eluden la responsabilidad afirmando que no contratan a niños trabajadores sino que subcontratan con otra empresa local, a la cual consideran como responsable de cumplir las normas.

Evidentemente que si una empresa tiene Responsabildad Social Corporativa, debe observarla en toda su cadena y en todos los trabajadores que fabrican sus productos, no sólo en la plantilla directa.

En la industria de las alfombras, por ejemplo, se ha asentado un tópico; los niños son considerados trabajadores muy aptos para tejer alfombras ya que sus pequeños dedos se adaptan mejor al trabajo atando nudos sobre los hilos tensados. Es falso que los niños tengan más habilidad para determinados trabajos por el tamaño de sus manos, en el caso de las alfombras necesitan un aprendizaje y una experiencia igual que los adultos para adquirir destreza.

En el sector juguetero, el $80 \%$ de los juguetes de todo el mundo se fabrica en China, Tailandia e Indonesia producidos por niños que no juegan.
Cerca de un $15 \%$ de los trabajadores del sector turístico son niños. Trabajan como botones en los hoteles, lavaplatos en restaurantes, limpiadores de playa, vendedores en las calles de artículos para turistas, cadis en los campos de golf, etc.

También hay niños trabajando en la construcción; la familia vive en el mismo lugar de la obra y se emplea en ella toda la familia, incluidos los niños. $\mathrm{Al}$ ser una actividad que requiere fuerza y técnica, los niños se ocupan de fabricar ladrillos, preparan la arcilla y la colocan en un molde.

Si la precariedad laboral conduce a la accidentalidad entre los adultos, lógicamente entre los niños también. No existen cifras medianamente fiables del número de niños que mueren en accidente de trabajo. Además de las muertes a causa de un accidente, en general los niños trabajadores tienen una tasa más alta de mortalidad, lo que incentiva más la natalidad en consecuencia más pobreza. De esta manera se cierra otro de los círculos en torno al trabajo infantil.

\section{EXTENSIÓN DE LA EDUCACIÓN: TAREA PRIORITARIA}

Hoy como en siglos pasados el trabajo obliga a muchos niños a abandonar la escuela, en el mejor de los casos a hacerla compatible con el trabajo. El rendimento escolar de estos niños siempre será menor que el rendimento de los niños no trabajadores. Los niños que compatibilizan el trabajo y la escuela; se ausentan con más frecuencia de la escuela, las notas obtenidas son más bajas, tienen más posibilidades de repetir curso y finalmente abandonan los estudios.

La necesidad de aportar ingresos a la economía familiar impone como una prioridad el trabajo sobre la educación, por lo que nunca saldrán de la pobreza.

Por no haber asistido a la escuela o haber abandonado prematuramente los estudios, tienen baja cualificación laboral y por tanto menos posibilidades de acceder a trabajos bien remunerados. Además verán como algo normal que sus propios hijos trabajen. Analfabetos de por vida, no podrán defender sus derechos ni siquiera cuando sean adultos, es una forma de cerrar el círculo.

En 2004 había en el mundo 121 millones de niños sin escolarizar ${ }^{20}$. A diferencia de lo que ocu- 
rre en los países ricos donde la mujer tiene mayor presencia en el sistema educativo, sobre todo en el nivel superior, entre los millones de niños sin escolarizar en el mundo la tasa más elevada corresponde a las niñas (con una diferencia neta de 9 millones).

Una vez más se comprueba que la mujer es más vulnerable a la pobreza. La Unicef advierte que con el analfabetismo aumenta la mortalidad y la explotación sexual.

La escolarización de las niñas contribuye a reducir la mortalidad infantil, reduciendo el porcentaje de niñas-madres o al menos retrasándola. Es una doble inversión la escolarización de las niñas porque las mujeres que han ido a la escuela tienden también a enviar a sus hijos/as. Además las mujeres que han recibido educación más de siete años se casan 4 años más tarde y tienen 2,2 veces menos hijos ${ }^{21}$.

La legislación en materia de educación cumple un importante papel subsidiario de la legislación laboral, pues se puede comprobar en la historia del trabajo infantil a través de las diferentes legislaciones en distintos países, que alli donde la educación es obligatoria la cifra de trabajo infantil es menor.

Ciertamente se dan situaciones diferentes; países o zonas con inversión en infraestructuras que producen una elevada oferta de trabajo fundamentalmente en el sector terciario, los jóvenes encuentran una fácil alternativa para obtener ingresos, influidos también por el grupo de pares, aquí la escuela es incapaz de mantener a los niños/jóvenes en el sistema.

\section{PARA ACABAR CON EL TRABAJO INFANTIL}

El trabajo infantil puede desaparecer creando más oportunidades laborales para los adultos y sus comunidades: hay que romper el círculo de la pobreza. Para ello es fundamental un cambio en la estrategia productiva. Pero la lógica de la economía globalizada es simple: los bienes se producen allí donde más baratos resultan y se venden allí donde el beneficio es mayor.

Estos empresarios en contrapartida se encuentran con países en los que la industrialización pasa por ofrecer mano de obra barata como forma de atracción para que las inversiones extranjeras se instalen en su territorio; crean empleo en zonas donde la pobreza y el desempleo es elevado.
El empleo creado es generalmente de escasa cualificación, con salarios bajos como punto de partida, pero además la sobreoferta de mano de obra hace que los salarios bajen aún más. Por lo que finalmente los terminan realizando las mujeres y los niños. La esperada prosperidad no se produce.

Los países aspirantes al desarrollo se encuentran con trabajadores de bajos ingresos, sin cualificación, analfabetos y posiblemente enfermos o inválidos a consecuencia del trabajo, así la pobreza del país se incrementa.

Existe además un factor exógeno de gran peso; la deuda extena. Debido a la deuda externa en muchos países se produce una sobreexplotación de los ecosistemas y de los trabajadores. El objetivo es producir más a menor coste para competir mejor en el mercado internacional. El propio FMI y el Banco Mundial "aconseja" a los países endeudados a trabajar más, vender más y consumir menos para ahorrar y pagar la deuda. Esto se relaciona también con el trabajo infantil de manera que los propios gobiernos conocen su existencia pero son permisivos con el fenómeno.

\section{¿CÓMO INTERVENIR?}

Si se establece una relación de situaciones que dan lugar a que los niños trabajen en diferentes partes del mundo, se puede correlativamente establecer las medidas correctoras, algunas de las causas son:

La desigual distribución de la riqueza.

La inexistencia de políticas públicas en muchos países.

El abandono del "Estado de Bienestar" por parte de las políticas neoliberales en los países desarrollados.

La ausencia de programas que refuercen a la familia; el trabajo infantil es un sintoma de desprotección familiar.

El avance del sector informal de la economía

El fracaso del sistema educativo donde no se contempla la diversidad cultural (por ejemplo en los países desarrollados el mayor porcentaje de niños trabajadores son hijos de inmigrantes).

(21) 2005. UNICEF, Inforne sobre Los matrimonios prematuros. 
Algunas de las medidas concretas que se pueden adoptar por parte de los Estados adquiriendo verdaderos compromisos en la práctica son:

Lanzar un mensaje claro: el trabajo infantil siempre es negativo

Establecer una educación primaria universal y obligatoria.

Promover la igualdad entre géneros.

Promover el empleo rural, haciendo éste atractivo para los jóvenes en sustitución de los niños.

Ampliar la protección legal de los niños.

Establecer actuaciones legales severas para los empleadores de niños.

Crear conciencia entre el empresariado de que son responsables de sus trabajadores y de las condiciones en que éstos trabajan en toda la cadena, incluidos los trabajadores indirectos.

Crear etiquetas de garantia social : garantizan las condiciones sociales de la fabricación del producto (respetando los derechos de los trabajadores y del niño).

Los países industrializados deben comprometerse a no adquirir productos en los que ha intervenido mano de obra infantil mediante códigos de conducta que impidan la circulación de los productos fabricados por niños.

La implantación de medidas requiere de la colaboración de todos; Estados, sindicatos, ONG'S, OIT, OMS, UNICEF, OMC, FMI, consumidores, empresarios y multinacionales, pero no siempre hablan el mismo lenguaje.

Los propios Estados deben fomentar el registro de nacimientos, una recogida de datos fiables sobre la población y su edad, mejorando los sistemas estadísticos nacionales como punto de partida. Es una medida importante y básica para combatir el trabajo infantil la información sobre el mismo; crear sistemas de registro y seguimiento de los niños.

La OMS tiene que incidir en la erradicación o al menos el control de determinadas enfermedades. Uno de los programas de la OIT para la eliminación del trabajo infantil (IPEC) detectó que en Africa muchos niños trabajaban porque sus padres infectados por el virus del SIDA no podían hacerlo. El SIDA ha alterado la vida de millones de niños en el mundo. En el año 2007 más de 2 millones vivían con SIDA y unos 15 millones habían perdido a sus progenitores; madre o padre o ambos, a causa de esa enfermedad ${ }^{22}$.

La OMC ante el dilema de que para sobrevivir los niños y sus familias tienen que vender, si por solidaridad con los niños no se compran los productos por estar fabricados por mano de obra infantil, se desencadena un aumento de la pobreza. Ante esta disyuntiva se pueden establecer acuerdos internacionales sobre precios y salarios fomentando el comercio justo. La marca UE (gran mercado) solamente la podrían obtener esos productos y no aquellos productos en los que el proceso de producción no es trasparente. Un mayor control sobre las multinacionales es necesario, pues no son las empresas pequeñas las que se deslocalizan. En definitiva adoptar códigos de conducta que garanticen en todo el mundo el respeto a los derechos del trabajo y a las convenciones de la OIT.

La legislación junto con la inspección del trabajo es la respuesta más importante de las Administraciones Públicas contra el trabajo infantil. Detectar y perseguir la picaresca, por ejemplo el caso de los aprendices. Muchos países contemplan en su legislación que los niños de 14 a 16 años pueden trabajar como aprendices, en la páctica es una vía para emplear a niños. Cuando se realiza una inspección de trabajo y encuentran niños trabajando, la respuesta es la misma siempre: los niños no son trabajadores de la hacienda "son ayudantes de sus padres".

Los medios de comunicación tienen un importante papel social informando sobre la situación en la que se encuentran millones de niños, junto con las diferentes campañas de la UNICEF y la OIT pueden incidir en la sensibilización de la opinión pública que a su vez puede presionar para la adopción de medidas sobre todo gubernamentales mediante la promulgación de leyes y el establecimiento de más vigilancia y control sobre estas prácticas.

La lucha contra el trabajo infantil es posible mediante proyectos globales entre administraciones públicas, asociaciones empresariales, asociaciones de exportadores, cámaras de comercio, sindicatos, ONG'S, organismos internacionales (OIT, OMC,

(22) 2008. OMS-UNICEF, Informe abril . 
OMT, UNICEF, etc) medios de comunicación y los propios ciudadanos.

\section{CONCLUSIONES}

El trabajo infantil atenta contra los Derechos del niño, no permite al menor desarrollarse adecuadamente tanto física como psíquicamente; además será una dificultad añadida a su vida de adulto. El trabajo para el niño no es un acto voluntario, no tienen criterio para tomar decisiones, por lo que si trabajan es porque están obligados a ello.

El trabajo infantil surge por la degradación de las condiciones sociales, económicas y culturales en el primer mundo, donde la protección del Estado de Bienestar ha fallado, la dinámica del desarrollo local no se ha consolidado sumado a que las tendencias productivas se caracterizan por la deslocalización.
No se debe criminalizar a las familias, aunque sean éstas las que permiten e incluso fomentan el trabajo de sus hijos. Hay que considerar a la familia como parte de la solución, la ayuda a la familia debe ser un eje de las políticas públicas. Los Estados fallan en sus políticas de integración de los dos espacios de contención por excelencia del trabajo infantil: la familia y la escuela.

En cuanto a la familia se deben diseñar políticas sociales de inclusión y asistencia sobre las causas que originan la pobreza, en paralelo a unas políticas escolares capaces de intervenir en el abandono escolar.

Finalmente y para concluir, para que los niños no trabajen se necesita una sociedad más justa. Sería una esperanza para millones de niños alcanzar la eliminación de las peores formas de trabajo infantil antes del año 2016, fecha que la OIT ha puesto como objetivo.

\section{BIBLIOGRAFIA}

Borrás, J.M. Actitudes patronales ante la regulación del trabajo infantil en el tránsito del siglo XIX al XX. Hispania, Revista de Historia, 1995, n 190 pp 629-644.

Borrás Llop, J.M. El trabajo infantil en el mundo rural entre 1849 y 1936. en José Miguel MARTÍNEZ CARRIÓN (editor), El nivel de vida en la España Rural, siglos XVIII-XX. Universidad de Alicante, Alicante, 2002.

Camps, E. Trabajo infantil y estrategias familiares durante los primeros estadios de la industrialización catalana (1850-1925), Cuadernos de Historia Contemporanea, 2002, $\mathrm{n}^{\circ} 24$ pp 263-279.

CASTILLO, S. (estudio introductorio): Reformas Sociales. Información oral y escrita publicada de 1889 a 1893, Madrid, Ministerio de Trabajo y Seguridad Social, 1985.

De la CALLE VELASCO, Ma D. "Sobre los orígenes del Estado Social en

España", en ESTEBAN DE VEGA, M. (ed.): Pobreza, beneficencia y política social. Ayer, 1997, $\mathrm{n}^{\mathrm{o}} 25$.
FNUAP: El estado de la población en el mundo, 2005.

INSTITUTO DE REFORMAS SOCIALES: Legislación del trabajo, hasta junio de 1905, Madrid.

INSTITUTO DE REFORMAS SOCIALES: Legislación sobre el descansodominical, Madrid, Sobrinos de la sucesora de M. Minuesa de los Ríos, 1924.

MAN, S. El silencio de la inocencia. Barcelona, Ediciones Destino, 2006.

MEGALE, A. y TESILLI, A. Minori al lavoro; il caso dei minori migranti. Roma, IRES- Save the Childen, edisse, 2007.

MOKYR, J. La revolución indusrtrial y la nueva historia económica, Revista de Historia económica,1987, n 5 pp 441-482.

MONTERO, F. La polémica sobre el intervencionismo y la primera legislación obrera en España, 1890-1900. Primera parte: El debate académico, Revista de Trabajo, 1980, núms. 59-60. 
MONTERO, F. La polémica sobre el intervencionismo y la primera legislación obrera en España, 1890-1900. Segunda parte: El debate político-parlamentario, Revista de Trabajo, 1981, núms. 61-62.

MONTOYA MELGAR, A. Ideología y lenguaje de las primeras leyes laborales de España, Madrid, Civitas, 1975.

NATS: (Informe), Los niños y adolescentes: trabajadores organizados. Lima, 2003.

OIT: ¿ayudantes o esclavos? Comprender el trabajo infantil doméstico y cómo intervenir. Ginebra, 2004.

OIT: Informe anual del día mundial contra el trabajo infantil. Ginebra, 2007.

OIT: La eliminación del trabajo infantil. Revista Trabajo, 2007, nº 61. Ginebra,

OIT: Las cosechas del futuro sin trabajo infantil. Revista Trabajo, 2007, $\mathrm{n}^{\circ}$ 61. Ginebra.

OMS/UNICEF: Informe sobre el sida en el mundo. División de estadística de las Naciones Unidas, 2008.

PALOMEQUE, M. "La intervención normativa del Estado en la "cuestión social" en la España del siglo XIX", en ESTEBAN DE VEGA, M. (ed): Pobreza, beneficencia y política social. Ayer,1997, $\mathrm{n}^{\mathrm{o}} 25$.
TUNON DE LARA, M. El movimiento obrero en la historia de España, Madrid, Taurus, 1972. 2005.

UNICEF: Early Marriege: traditional Practice,

UNICEF: Estado Mundial de la Infancia, Años; 2004, 2005, 2006, 2007, 2008.

VV.AA. Sin descanso: abusos contra los niños trabajadores domésticos. Nueva York, Ed. Human Rights Watch, 2004.

VV.AA. Oidos sordos:trabajo infantil peligroso en el cultivo de caña de azúcar en El Salvador. Nueva York, Ed. Human Rights Watch, 2007.

VALIENTE, C. "Políticas públicas de género en perspectiva comparada. La mujer trabajadora en Italia y España (1900-1996)", Madrid, UAM, 1997.

ZANCADA, P. El trabajo de la mujer y el niño, Madrid, Mariano Núñez Camper editor, 1904.

www.ilo.org/childlabour

www.ei-ie.org/es/index

www.mte.gov.br.drt

www.mnmmr.org.br

www.wto.org/indexp.htm

www.ifejant.org 